\title{
Mechanisms used to restore ventilation after partial upper airway collapse during sleep in humans
}

\author{
Amy S Jordan, Andrew Wellman, Raphael C Heinzer, Yu-Lun Lo, Karen Schory, Louise Dover, Shiva \\ Gautam, Atul Malhotra, David P White
}

Thorax 2007;62:861-867. doi: 10.1136/thx.2006.070300

See end of article for authors' affiliations

Correspondence to: Dr Amy S Jordan, Sleep Disorders Program @ BIDMC, 75 Francis St, Boston, Massachusetts 02115, USA; ajordan@rics. bwh.harvard.edu

Received 12 August 2006 Accepted 28 March 2007

Published Online First 5 April 2007

\begin{abstract}
Background: Most patients with obstructive sleep apnoea (OSA) can restore airflow after an obstructive respiratory event without arousal at least some of the time. The mechanisms that enable this ventilatory recovery are unclear but probably include increased upper airway dilator muscle activity and/or changes in respiratory timing. The aims of this study were to compare the ability to recover ventilation and the mechanisms of compensation following a sudden reduction of continuous positive airway pressure (CPAP) in subjects with and without OSA.

Methods: Ten obese patients with OSA (mean (SD) apnoea-hypopnoea index 62.6 (12.4) events/h) and 15 healthy non-obese non-snorers were instrumented with intramuscular genioglossus electrodes and a mask/ pneumotachograph which was connected to a modified CPAP device that could deliver either continuous positive or negative pressure. During stable non-rapid eye movement sleep the CPAP was repeatedly reduced 2-10 $\mathrm{cm} \mathrm{H}_{2} \mathrm{O}$ below the level required to eliminate flow limitation and was held at this level for 5 min or until arousal from sleep occurred.

Results: During reduced CPAP the increases in genioglossus activity $(311.5(49.4) \%$ of baseline in subjects with OSA and $315.4(76.2) \%$ of baseline in non-snorers, $p=0.9)$ and duty cycle (123.8 (3.9)\% of baseline in subjects with OSA and $118.2(2.8) \%$ of baseline in non-snorers, $p=0.4)$ were similar in both groups, yet patients with OSA could restore ventilation without cortical arousal less often than non-snorers $154.1 \%$ vs $65.7 \%$ of pressure drops, $p=0.04$ ). When ventilatory recovery did not occur, genioglossus muscle and respiratory timing changes still occurred but these did not yield adequate pharyngeal patency/ventilation. Conclusions: Compensatory mechanisms (increased genioglossus muscle activity and/or duty cycle) often restore ventilation during sleep but may be less effective in obese patients with OSA than in non-snorers.
\end{abstract}

U ntil recently the restoration of airflow which terminates each apnoea or hypopnoea in obstructive sleep apnoea (OSA) was thought to require an arousal from sleep, such that the upper airway dilator muscles could become active and open the collapsed airway. However, Younes ${ }^{1}$ has reported that, although arousal does occur before termination of $61 \%$ of respiratory events induced by a sudden reduction in continuous positive airway pressure (CPAP), flow increased before arousal in $22 \%$ of CPAP drops and the upper airway reopened without arousal in $17 \%$ of trials. ${ }^{1}$ These data suggest that compensatory mechanisms exist during sleep which can overcome the reduced upper airway patency, such that increases in ventilation can occur without arousal at least some of the time.

These compensatory mechanisms may include increased inspiratory airflow or changes in respiratory timing with increases in either inspiratory time or breathing frequency. Combinations of these responses are also possible. In a flow limited pharyngeal airway, increased inspiratory flow requires improvements in upper airway patency, most likely via activation of upper airway dilator muscles. One such dilator muscle, the genioglossus, has reduced reflex responsiveness to respiratory stimuli during sleep..$^{2-5}$ However, it can be activated by combinations of chemical and mechanical stimuli during sleep in healthy subjects $^{67}$ and increases during obstructive respiratory events in patients with OSA. ${ }^{8}{ }^{9}$ Whether this increased genioglossus activity improves airflow and restores ventilation is unclear. In a report of five healthy subjects in whom continuous negative airway pressure (CNAP) was applied during sleep to induce airway collapse, ventilation did not increase until arousal from sleep occurred despite increased genioglossus activity. ${ }^{10}$ Similarly, changes in respiratory timing following application of an external resistive load or CNAP are also reduced during sleep compared with wakefulness. ${ }^{111}$ However, small changes do occur in response to upper airway collapse, resistive loading and hypercapnia. ${ }^{10-12}$ Whether these changes are sufficient to reestablish ventilation so that arousal does not occur is unclear.

The aims of this study were (1) to investigate the mechanisms used to restore ventilation after partial upper airway collapse in individuals with and without OSA and (2) to compare the effectiveness of these mechanisms in restoring ventilation during sleep between the two groups. We hypothesised that subjects both with and without OSA would be able to restore ventilation at least some of the time during sleep, but that the restoration of ventilation would require larger increases in muscle activity or respiratory timing in patients with OSA than in non-snorers. We induced a range of upper airway collapse in both groups because the compensatory mechanisms and the effectiveness of the mechanisms are likely to vary with severity of airway collapse.

\section{METHODS}

Additional methodological details and rationale are given in the online supplement available at http://thorax.bmj.com/supplemental.

\footnotetext{
Abbreviations: CNAP, continuous negative airway pressure; CPAP, continuous positive airway pressure; $\mathrm{EMG}_{\mathrm{GG}}$, genioglossal electromyogram; $F_{B}$, breathing frequency; NREM, non-rapid eye movement; OSA, obstructive sleep apnoea; $\mathrm{PETCO}_{2}$, end-tidal partial pressure of $\mathrm{CO}_{2}, \mathrm{P}_{C \mathrm{CIT}}$, pharyngeal critical closing pressure; $P_{E P I}$, epiglottic

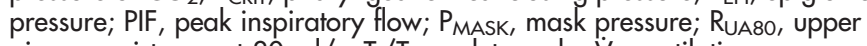
airway resistance at $80 \mathrm{ml} / \mathrm{s} ; \mathrm{T}_{\mathrm{I}} / \mathrm{T}_{\mathrm{TOT}}$, duty cycle; $\mathrm{Vl}_{\mathrm{l}}$, ventilation
} 


\section{Subjects}

Eleven patients with at least moderately severe treated OSA and 19 healthy non-snorers (snore $<3$ nights/week) provided informed consent and participated in the study. All participants were aged 20-65 years, were non-smokers and without cardiorespiratory or sleep disorders other than OSA. The subjects were recruited from the community and our sleep laboratory by flyers and word of mouth. The study was approved by the human research committee of the Brigham and Women's Hospital.

\section{Procedures}

Subjects lay supine wearing a nasal mask with a pneumotachograph and differential pressure transducer for assessment of inspired flow, breath timing and ventilation ( $\left.\dot{V}_{I}\right)$. The pneumotachograph was connected to a leak valve and a modified CPAP device which delivers either CPAP or CNAP. The expirate was continuously sampled from one nostril to determine the endtidal partial pressure of $\mathrm{CO}_{2}\left(\mathrm{PETCO}_{2}\right)$. Mask pressure $\left(\mathrm{P}_{\mathrm{MASK}}\right)$ was continuously monitored and epiglottic pressure $\left(\mathrm{P}_{\mathrm{EPI}}\right)$ measured as previously described ${ }^{13}$ with a pressure tipped catheter. Upper airway resistance (epiglottis to mask) was measured at $80 \mathrm{ml} / \mathrm{s}\left(\mathrm{R}_{\mathrm{UA} 80}\right)$ because this flow generally occurred before the onset of flow limitation. Intramuscular genioglossal electromyogram $\left(\mathrm{EMG}_{\mathrm{GG}}\right)$ was recorded in the standard manner, ${ }^{14}$ expressed as the percentage of maximum and reported as the peak value during inspiration (Peak) and minimum value during expiration (Tonic). Sleep and arousals were scored based on two channel electroencephalogram (C3$\mathrm{A} 2, \mathrm{O} 2-\mathrm{Al})$, left and right electro-occulogram and submental electromyogram. ${ }^{15} 16$ Oxygen saturation and the ECG were recorded for safety purposes.

Subjects were initially placed on CPAP at the prescribed level (subjects with OSA) or $4 \mathrm{~cm} \mathrm{H}_{2} \mathrm{O}$ (non-snorers). Following sleep onset, CPAP was increased $2 \mathrm{~cm} \mathrm{H}_{2} \mathrm{O}$ above the level that abolished flow limitation (optimal CPAP) and remained at this level for $5 \mathrm{~min}$. Flow limitation was defined as a drop in $\mathrm{P}_{\mathrm{EPI}}$ of $1 \mathrm{~cm} \mathrm{H}_{2} \mathrm{O}$ with no increase in airflow. The CPAP was then lowered $2 \mathrm{~cm} \mathrm{H}_{2} \mathrm{O}$ for 5 min or until arousal from sleep, after which the optimal CPAP was reapplied until 3 min of stable sleep occurred. The CPAP was reduced to progressively lower levels (as much as $10 \mathrm{~cm} \mathrm{H}_{2} \mathrm{O}$ ) in this manner 10 or more times during non-rapid eye movement (NREM) sleep.

\section{Data analyses}

Pressure drops were only analysed if no leak was present, if flow limitation developed during the trial and if no arousal occurred during the first three breaths of reduced CPAP. For the remaining pressure drops, ventilatory recovery was considered to have occurred if the subject remained asleep for the full 5 min or if $\mathrm{P}_{\mathrm{EPI}}$ and $\mathrm{PETCO}_{2}$ were both stable $\left(<2 \mathrm{~cm} \mathrm{H}_{2} \mathrm{O}\right.$ drop in $\mathrm{P}_{\mathrm{EPI}},<2 \mathrm{~mm} \mathrm{Hg}$ rise in $\mathrm{PETCO}_{2}$ ) for $30 \mathrm{~s}$ before a cortical arousal (spontaneous arousals). However, if an arousal occurred in the setting of increasing respiratory drive $\left(>2 \mathrm{~cm} \mathrm{H}_{2} \mathrm{O}\right.$ fall in $\mathrm{P}_{\mathrm{EPI}}$ ) or rising $\mathrm{PeTCO}_{2}(>2 \mathrm{~mm} \mathrm{Hg})$, the arousal was assumed to be a result of inadequate ventilation due to airway collapse and no recovery of ventilation was considered to have occurred. A secondary analysis was also conducted where pressure drops in which airflow increased $>20 \%$ immediately before cortical arousal were considered to have ventilatory recovery. In both analyses the proportion of pressure drops which recovery occurred were compared between groups with the $\chi^{2}$ test and two-way ANOVA for repeated measures for each $1 \mathrm{~cm} \mathrm{H}_{2} \mathrm{O}$ drop in CPAP or $1 \mathrm{~cm} \mathrm{H} \mathrm{H}_{2} \mathrm{O} / \mathrm{l} / \mathrm{s}$ rise in $\mathrm{R}_{\mathrm{UA80}}$. In addition, the mean recovery rate was calculated for each subject and compared between groups using the unpaired Student $t$ test.
The mechanisms of compensation (respiratory timing changes and increased $E M G_{G G}$ ) during the first and last three breaths (before cortical arousal or at $5 \mathrm{~min}$ if no arousal) following pressure drops were compared between groups and between recovery and no recovery trials with two-way ANOVA for repeated measures. Tukey post hoc tests were used wherever significant ANOVA effects were found. In addition, the slope and intercepts of the $\mathrm{P}_{\mathrm{EPI}} / \mathrm{EMG}_{\mathrm{GG}}$ relationships were compared between groups during pressure drops, with and without recovery. Pharyngeal critical closing pressure $\left(\mathrm{P}_{\text {CRIT }}\right)$ was measured as previously reported, ${ }^{17}{ }^{18}$ and the slope of the peak inspiratory flow (PIF)/P $\mathrm{P}_{\text {MASK }}$ relationship was compared between groups with the Student $t$ test. Mean (SE) values are presented and a $\mathrm{p}$ value of $<0.05$ was considered statistically significant.

\section{RESULTS}

\section{Subject characteristics}

Three subjects failed to achieve stable sleep in the laboratory. Two subjects recruited as non-snorers were found to have flow limitation on $4 \mathrm{~cm} \mathrm{H}_{2} \mathrm{O}$ and were therefore taken off CPAP for $30 \mathrm{~min}$ to ensure they did not have OSA. During this time one subject was observed to have repetitive hypopnoeas and arousals so his data were excluded because the true severity of OSA was unknown and he was untreated, unlike the other patients with OSA. The modified CPAP device malfunctioned during another study leaving 25 subjects ( 10 with OSA ( 5 men) and 15 non-snorers ( 8 men $)$ ) with adequate data.

The subjects with OSA tended to be older than the nonsnorers (44.8 (3.3) and 36.1 (2.8) years, respectively, $\mathrm{p}=0.06)$, but had significantly greater body mass indices (35.9 (1.9) vs $\left.24.2(0.6) \mathrm{kg} / \mathrm{m}^{2}, \mathrm{p}<0.01\right)$. The patients had severe OSA (apnoea-hypopnoea index 62.6 (12.4) events/h) and significantly higher $\mathrm{P}_{\text {CRIT }}$ than non-snorers $\left(0.8(0.8)\right.$ vs -5.9 (1.0) $\mathrm{cm} \mathrm{H}_{2} \mathrm{O}$, $\mathrm{p}<0.01)$. However, the slope of the PIF/P $\mathrm{P}_{\text {MASK }}$ relationship did not differ between groups $\left(53.9(7.0) \mathrm{ml} / \mathrm{s} / \mathrm{cm} \mathrm{H}_{2} \mathrm{O}\right.$ in nonsnorers vs 63.9 (9.5) $\mathrm{ml} / \mathrm{s} / \mathrm{cm} \mathrm{H}_{2} \mathrm{O}$ in patients with OSA, $\mathrm{p}=0.4$ ), indicating that the same change in pressure probably produced a similar amount of ventilatory impairment in both groups. During stable sleep on optimal CPAP, respiratory timing and muscle activities did not differ between the groups (table 1). However, the optimal CPAP and resting $\dot{V}_{I}$ were significantly higher in obese patients with OSA (table 1).

A total of 333 pressure drops were included in the analysis ( 148 in patients with OSA and 185 in non-snorers, range 6-25 drops/subject). The average pressure drop was greater in nonsnorers than in patients with OSA $(-5.8(0.4)$ vs -4.1 (0.3) $\mathrm{cm} \mathrm{H}_{2} \mathrm{O}, \mathrm{p}<0.01$ ). However, the average $\mathrm{R}_{\mathrm{UAs0}}$ on the first three breaths of the pressure drops was not different between non-snorers and obese patients with OSA (3.7 (1.0) and $2.5(0.4) \mathrm{cm} \mathrm{H}_{2} \mathrm{O} / \mathrm{l} / \mathrm{s}$ respectively, $\left.\mathrm{p}=0.3\right)$. Examples of pressure drops where recovery and no recovery occurred are shown in fig 1 in the online supplement (available at http:// thorax.bmj.com/supplemental).

\section{Mechanisms of compensation for partial airway collapse}

Duty cycle $\left(\mathrm{T}_{\mathrm{I}} / \mathrm{T}_{\mathrm{TOT}}\right)$ and breathing frequency $\left(\mathrm{F}_{\mathrm{B}}\right)$ increased above the baseline level immediately following the pressure drop and remained raised for the duration of the drop (fig 1A and $\mathrm{B}$ ). These changes were due to an immediate reduction in expiratory time and a slower increase in inspiratory time (see fig 2 in online supplement available at http://thorax.bmj.com/ supplemental). In contrast, neither Peak nor Tonic $\mathrm{EMG}_{\mathrm{GG}}$ were significantly different from baseline on the first three breaths of reduced pressure. However, both variables increased by the end of the pressure drop (fig IC and D). There were no 
Table 1 Baseline data during stable NREM sleep on optimal CPAP in patients with and without OSA

\begin{tabular}{|c|c|c|}
\hline & $\begin{array}{l}\text { Obese OSA } \\
(n=10)\end{array}$ & $\begin{array}{l}\text { Non-snorers } \\
(n=15)\end{array}$ \\
\hline$\dot{V}_{1}(1 / \mathrm{min})^{*}$ & $7.6(0.5)$ & $6.3(0.2)$ \\
\hline VT (I) & $0.47(0.02)$ & $0.43(0.02)$ \\
\hline $\mathrm{F}_{\mathrm{B}}$ (breaths/min) & $16.3(0.9)$ & $14.9(0.6)$ \\
\hline $\mathrm{T}_{1} / \mathrm{T}_{\text {TOT }}$ & $0.43(0.02)$ & $0.40(0.01)$ \\
\hline$V_{T} / T_{1}(l / s)$ & $0.30(0.02)$ & $0.26(0.01)$ \\
\hline PIF $(\mathrm{l} / \mathrm{s})$ & $0.48(0.02)$ & $0.42(0.02)$ \\
\hline PETCO $_{2}(\mathrm{~mm} \mathrm{Hg})$ & $41.2(1.1)$ & $43.9(0.7)$ \\
\hline $\operatorname{CPAP}\left(\mathrm{cm} \mathrm{H}_{2} \mathrm{O}\right)^{*}$ & $11.5(0.7)$ & $5.7(0.5)$ \\
\hline$P_{E P I}\left(\mathrm{~cm} \mathrm{H}_{2} \mathrm{O}\right)$ & $-2.48(0.4)$ & $-1.48(0.2)$ \\
\hline EMG $G_{G G}$ Peak (\%max) & $2.8(1.1)$ & $4.1(1.0)$ \\
\hline $\mathrm{EMG}_{\mathrm{GG}}$ Tonic (\%max) & $1.0(0.4)$ & $1.3(0.4)$ \\
\hline
\end{tabular}

NREM, non-rapid eye movement; OSA, obstructive sleep apnoea; CPAP, continuous positive airway pressure; $\mathrm{V}_{\text {I, }}$ ventilation; $\mathrm{VT}_{\mathrm{T}}$, tidal volume; $\mathrm{T}_{\mathrm{I}} / \mathrm{T}_{\mathrm{TOT}}$, duty cycle; $\mathrm{F}_{\mathrm{B}}$, breathing frequency; PIF, peak inspiratory flow; $\mathrm{PETCO}_{2}$, endtidal partial pressure of $\mathrm{CO}_{2}, \mathrm{P}_{\mathrm{EP}}$, epiglottic pressure; $\mathrm{EMG}_{\mathrm{GG}}$, genioglossal electromyography;

Data shown as mean (SE) values.

${ }^{*} \mathrm{p}<0.05$ between groups.

statistically significant interaction effects between the groups for any of these variables, indicating that patients with OSA used similar compensatory mechanisms to the healthy nonsnorers. We acknowledge that with only 25 subjects we have limited power to detect interaction effects. However, none of the variables was significant using the Student $t$ test with Bonferroni corrections which suggests that the compensatory mechanisms are not different between groups.

\section{Ventilatory recovery during reduced CPAP}

Despite the fact that the mean pressure drop was larger in nonsnorers than in obese patients with OSA and the $\mathrm{EMG}_{\mathrm{GG}}$ and respiratory timing changes were similar in the two groups, ventilatory recovery occurred less often in patients with OSA than in non-snorers ( 80 trials $(54.1 \%)$ vs 122 trials $(65.7 \%)$, $\mathrm{p}=0.036)$. This finding persisted when the trials were divided into $1 \mathrm{~cm} \mathrm{H} \mathrm{H}_{2} \mathrm{O}$ CPAP bins or $1 \mathrm{~cm} \mathrm{H}_{2} \mathrm{O} / \mathrm{l} / \mathrm{s} \mathrm{R}_{\mathrm{UA80}}$ bins (fig 2, significant ANOVA main effect for subject group). Recovery was also reduced with larger pressure drops or $\mathrm{R}_{\mathrm{UA} 80}$ levels in both patients with OSA and non-snorers (significant ANOVA main effect for CPAP or $\mathrm{R}_{\mathrm{UA80}}$, respectively). However, there
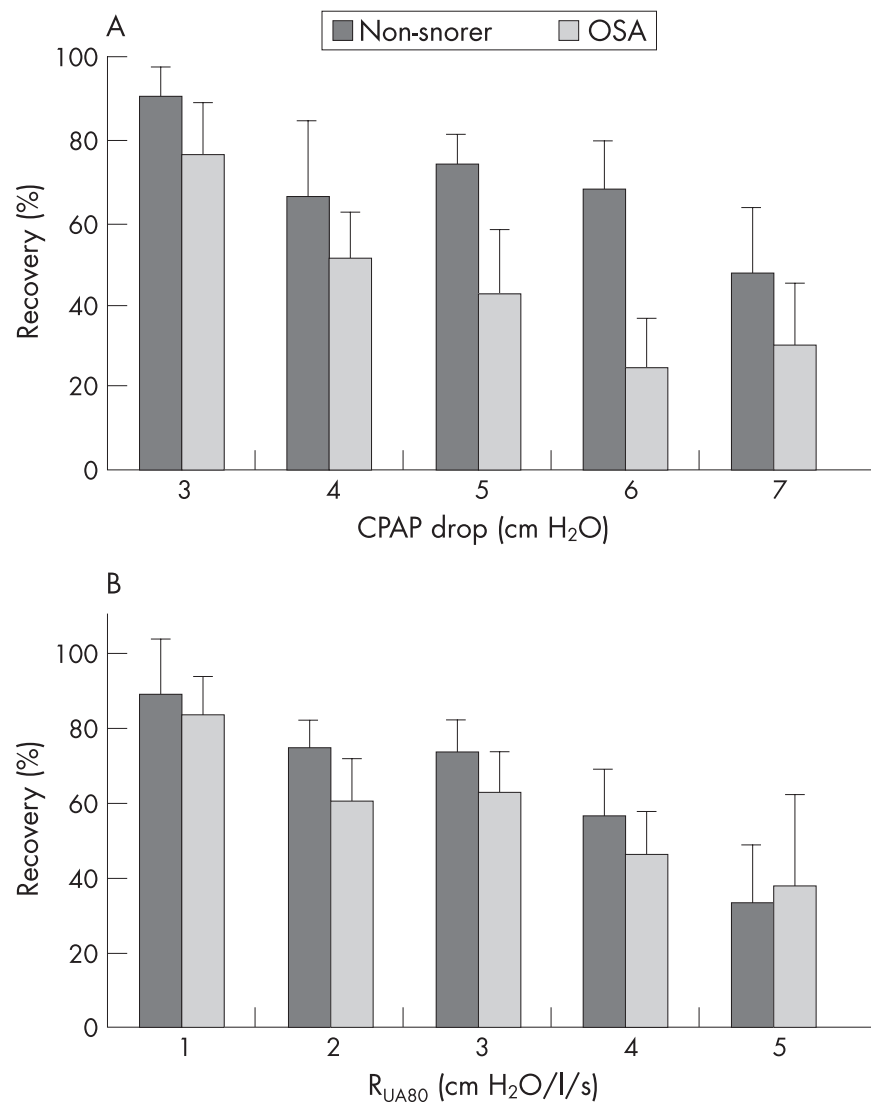

Figure 2 Ability to adequately restore ventilation (\% recovery) in patients with obstructive sleep apnoea (OSA) and non-snorers at (A) different levels of reduced continuous positive airway pressure (CPAP) or (B) increased upper airway resistance at $80 \mathrm{ml} / \mathrm{s}$ (RUA80). The R RA80 levels were determined as the average of the first three breaths during reduced CPAP. Patients with OSA had a lower rate of recovery at all CPAP and RUA80 levels (significant ANOVA group effects). Both groups had reduced recovery rates as the CPAP drop or RUA80 levels increased (significant effect of CPAP or RUA80 level). Data are only shown for CPAP and RUA80 levels in which there were at least six trials in both groups.

were no significant interaction effects, which suggests that the reduction in recovery with increasing pressure drop or $\mathrm{R}_{\mathrm{UA} 80}$ was similar between the two groups. The mean recovery rate
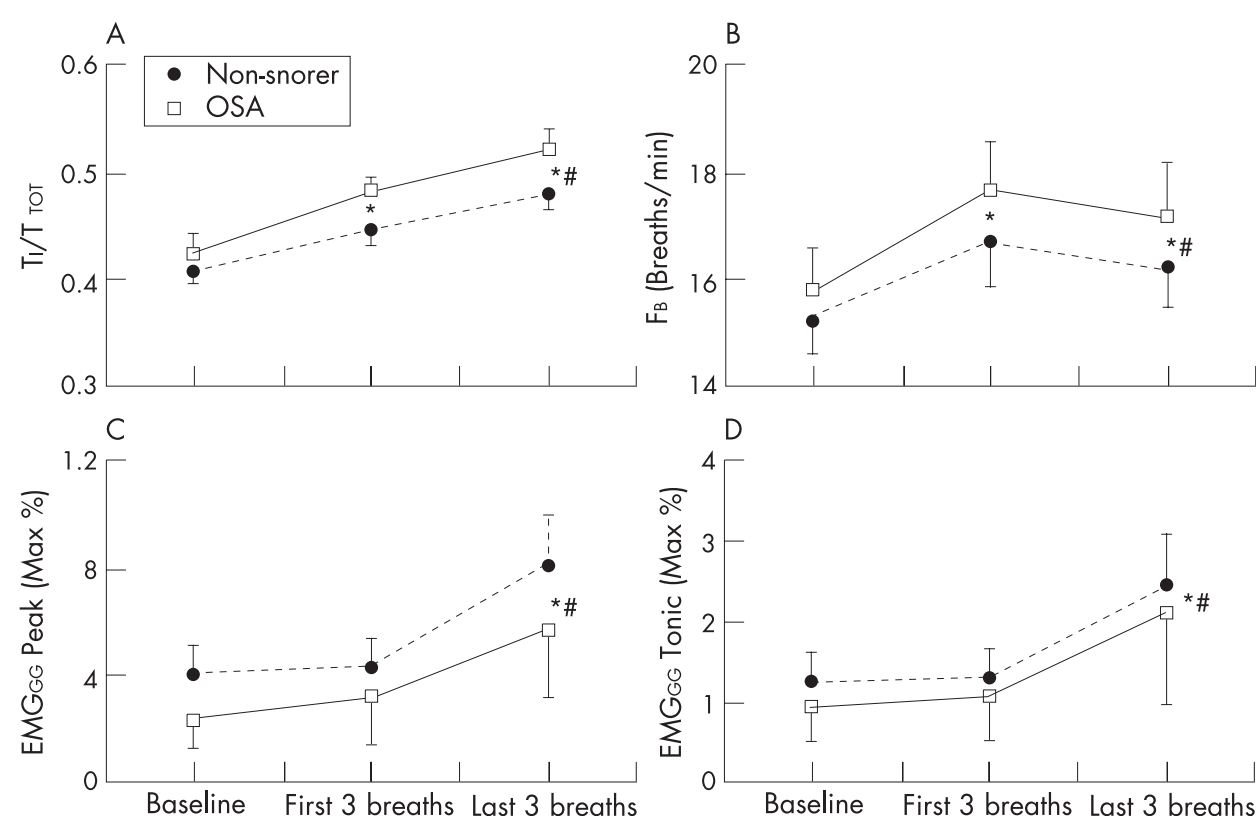

Figure 1 Changes in (A) duty cycle $\left(T_{1}\right)$ $\mathrm{T}_{\text {TOT }}$ ), (B) breathing frequency $\left(\mathrm{F}_{\mathrm{B}}\right)$ and $(\mathrm{C})$ Peak and (D) Tonic genioglossus muscle activity (EMG $G_{G G}$ ) in the $60 \mathrm{~s}$ before reduction in continuous positive airway pressure (CPAP) (baseline) and on the first three and last three breaths of reduced CPAP in 10 patients with OSA and 15 non-snoring subjects. The last three breaths are the average of the last three breaths before arousal or at the end of reduced CPAP if no arousal occurred. Mean (SE) values are presented. ${ }^{*} p<0.05$ vs baseline for both groups; $\# p<0.05$ vs the first three breaths for both groups. 

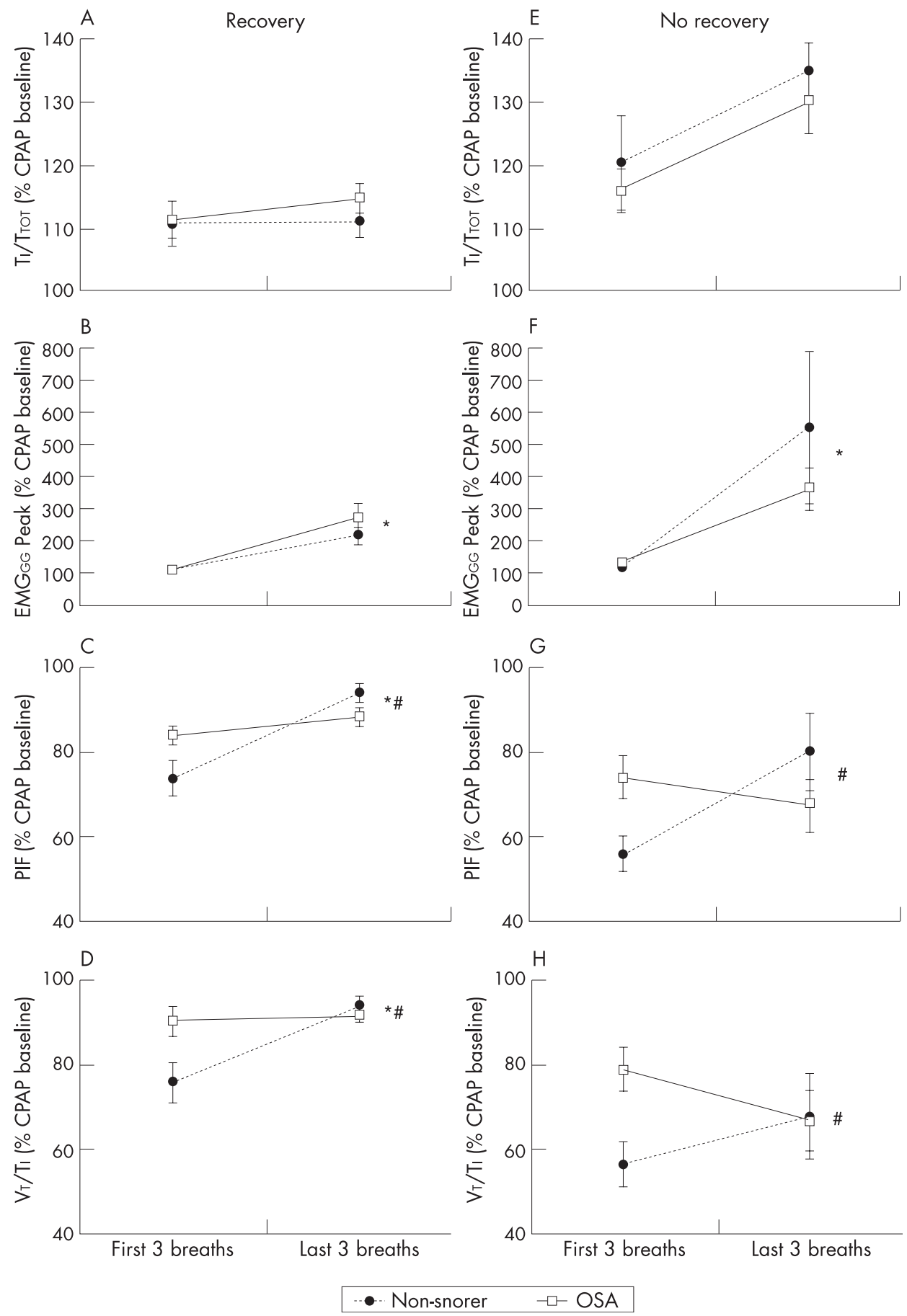

Non-snorer
Figure $3(\mathrm{~A}, \mathrm{E})$ Duty cycle $\left(\mathrm{T}_{\mathrm{l}} / \mathrm{T}_{\mathrm{TOT}}\right),(\mathrm{B}, \mathrm{F})$ peak inspiratory genioglossus muscle activity (EMG $G_{G G}$ Peak), (C, G) peak inspiratory flow (PIF) and $(D, H)$ mean inspiratory flow $\left(V_{T} / T_{1}\right)$ flow in 10 patients with OSA and 15 nonsnoring controls when recovery of ventilation was (Recovery, A-D) and was not (No recovery, E-H) adequate. Mean (SE) values are presented. ${ }^{*} p<0.05$ first three breaths vs last three breaths; \# indicates that nonsnorers rose from the first to last three breaths more than patients with OSA (significant patient group by breath interaction effect). $†$ indicates that No Recovery trials had a significantly greater increase than Recovery trials when both groups were combined in a repeated measures ANOVA with breath and recovery as main factors. per subject also tended to be lower in the patients with OSA than in the non-snorers $(54.5(4.9) \%$ vs $67.7(5.1) \%, \mathrm{p}=0.08)$.

Only 26 no recovery trials were found to have an increase in airflow immediately before cortical arousal. It is possible that recovery was adequate in these trials but that the increase in flow caused the arousal. However, if these trials were considered to have adequate recovery (secondary analysis), we again found that obese patients with OSA could recover less often than non-snorers (91 trials $(61.5 \%)$ vs 137 trials $(74 \%)$, $\mathrm{p}=0.02$ ). In addition, if a very conservative estimate of recovery is used by just considering trials in which the subject slept for the full $5 \mathrm{~min}$, then patients with OSA were still found to have fewer trials with recovery than non-snoring subjects ( 33 trials $(22.3 \%)$ vs 63 trials $(34.1 \%), p=0.026)$. Thus, obese patients with OSA can recover ventilation less often than nonsnorers, regardless of the definition of recovery used.

When all the trials with recovery are compared between groups (fig $3 \mathrm{~A}-\mathrm{D}$ ), the reduction in pressure was significantly greater in non-snorers than in patients with OSA $(-5.7(0.4)$ vs $\left.-3.8(0.3) \mathrm{cm} \mathrm{H}_{2} \mathrm{O}, \mathrm{p}<0.01\right)$. However, the increase in $\mathrm{R}_{\mathrm{UA} 80}$ on the first three breaths was not different between the two groups (3.1 (0.9) in non-snorers and $2.1(0.3) \mathrm{cm} \mathrm{H}_{2} \mathrm{O} / \mathrm{l} / \mathrm{s}$ in OSA, $\mathrm{p}=0.3$ ). The compensatory mechanisms (increases in peak and tonic $\mathrm{EMG}_{\mathrm{GG}}, \mathrm{T}_{\mathrm{I}} / \mathrm{T}_{\mathrm{TOT}}$ and $\mathrm{F}_{\mathrm{B}}$ ) were again not different between patients with and without OSA when only the trials with recovery were considered $\left(\mathrm{T}_{\mathrm{I}} / \mathrm{T}_{\mathrm{TOT}}\right.$ and Peak $\mathrm{EMG}_{\mathrm{GG}}$ are shown in fig 3A and B). Despite these similar compensatory mechanisms, the non-snorers were able to increase both PIF and $V_{T} / T_{I}$ 


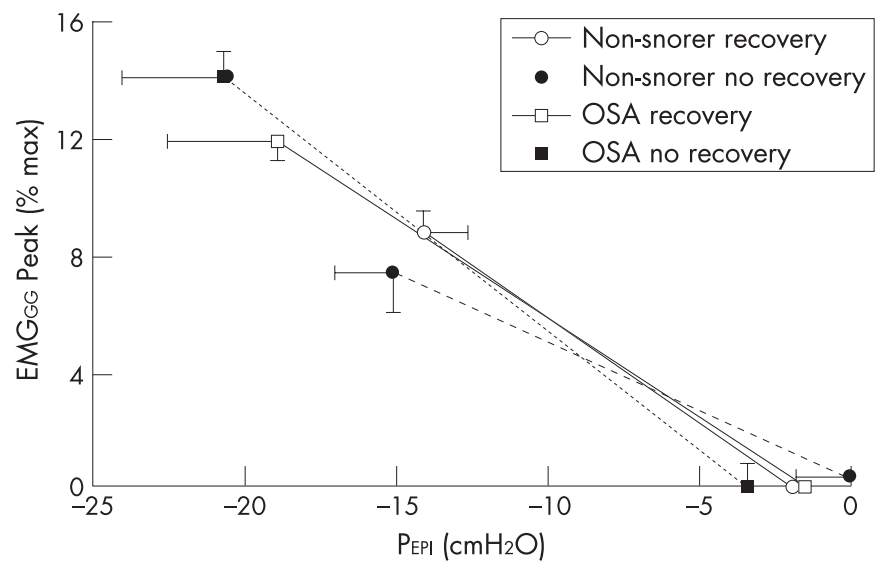

Figure 4 Average relationship between epiglottic pressure $\left(P_{E P I}\right)$ and peak inspiratory genioglossal EMG (EMG $G_{G G}$ Peak) in patients with obstructive sleep apnoea (OSA) and non-snorers during reduced continuous positive airway pressure (CPAP) when recovery of ventilation did and did not occur. $P_{E P I}$ and $E M G_{G G}$ Peak were plotted for every breath during CPAP drops in each subject and the slope and intercept of the linear regression determined for when recovery of ventilation did and did not occur. The mean regression lines are shown with the length of the line determined by the average minimum $P_{E P I}$ in each condition. The slopes, intercepts and minimum $P_{E P I}$ were not different in either group or recovery condition.

by the end of the pressure drop to a greater extent than obese patients with OSA (fig 3C and D).

Similarly, when the trials with no recovery were considered (fig $3 \mathrm{E}-\mathrm{H}$ ), the increases in $\mathrm{EMG}_{\mathrm{GG}}$ and $\mathrm{T}_{\mathrm{I}} / \mathrm{T}_{\mathrm{TOT}}$ were not different between patients with and without OSA (fig 3E and F). However, the non-snorers were able to increase airflow across the period of reduced pressure whereas patients with OSA had further declines in both peak and mean inspiratory flow (fig $3 \mathrm{G}$ and $\mathrm{H}$ ). These differences existed despite the change in CPAP being significantly greater in non-snorers $\left(-6.4(0.5)\right.$ vs $\left.-4.7(0.4) \mathrm{cm} \mathrm{H}_{2} \mathrm{O}, \mathrm{p}<0.01\right)$ and the initial increase in $\mathrm{R}_{\mathrm{UA} 80}$ being similar in both groups (5.1 (1.6) in nonsnorers vs $2.9(0.4) \mathrm{cm} \mathrm{H} \mathrm{H}_{2} \mathrm{O} / \mathrm{l} / \mathrm{s}$ in patients with OSA, $\mathrm{p}=0.2$ ).

\section{Mechanisms of compensation when no recovery occurred}

The increase in duty cycle was greater during pressure drops where no recovery occurred than when recovery did occur (fig $3 \mathrm{~A}$ and $\mathrm{E}$, both groups combined in a two-way repeated measures ANOVA with recovery and breath as the two factors). The increase in Peak (fig $3 \mathrm{~B}$ and $\mathrm{F}$ ) and Tonic $\mathrm{EMG}_{\mathrm{GG}}$ during the pressure drops were not significantly different between recovery and no recovery trials. However, $\mathrm{P}_{\mathrm{EPI}}$ was more negative during pressure drops where no recovery occurred. The relationships between $\mathrm{P}_{\mathrm{EPI}}$ and Peak $\mathrm{EMG}_{\mathrm{GG}}$ were therefore compared between pressure drops with and without recovery to assess whether the $\mathrm{EMG}_{\mathrm{GG}}$ was lower for any given $\mathrm{P}_{\mathrm{EPI}}$ when no recovery occurred (fig 4). The slopes and intercepts of these relationships were not significantly different between subject groups whether recovery occurred or not (no main or interaction effects), which suggests that the failure to restore ventilation was not related to impaired muscle responsiveness in either group.

The reduction in pressure was significantly greater in trials where there was no recovery than in trials where recovery occurred (-5.9 (0.4) and $-4.9(0.3) \mathrm{cm} \mathrm{H}_{2} \mathrm{O}$, respectively, $\mathrm{p}<0.01$ ) and, correspondingly, the average $\mathrm{R}_{\mathrm{UA} 80}$ measured on the first three breaths was higher during trials with no recovery than in those with adequate recovery $(4.2(1.0)$ and 2.7 (0.6) $\mathrm{cm} \mathrm{H}_{2} \mathrm{O} / \mathrm{l} / \mathrm{s}$, respectively, $\mathrm{p}<0.01$ ).

\section{DISCUSSION}

This study investigated the mechanisms used to restore ventilation when airway patency is reduced during stable sleep in patients with and without OSA, and the effectiveness of these mechanisms at increasing ventilation so that stable sleep could continue. The results indicate that changes in respiratory timing and genioglossus muscle activity do occur during partial upper airway collapse, and these changes are similar in patients with and without OSA. However, despite activation of these mechanisms, patients with OSA could restore airflow and ventilation less often than subjects without OSA. When ventilatory recovery did not occur, both subjects with and without OSA showed marked increases in duty cycle and genioglossus muscle activity before arousal. Thus, the inability to recover ventilation at some times was not due to failure of activation of the compensatory mechanisms but was probably due to greater severity of upper airway collapse (lower CPAP, higher $\mathrm{R}_{\mathrm{UA80}}$ ).

It is important to note that the patients with OSA were significantly heavier than the non-snoring subjects, and it is possible that the group differences reported were the result of obesity rather than OSA per se. In order to assess whether obesity was a confounder, we performed a linear regression analysis between body mass index and the percentage of CPAP drops with ventilatory recovery in each group. This relationship was not significant in either group $\left(\mathrm{p}>0.5\right.$ and $\mathrm{R}^{2}=0.04$ and 0.03 ). We therefore think it is unlikely that the difference in body mass index between patients and non-snorers significantly influenced our findings, although clearly this cannot be ruled out. Importantly, a large percentage of patients with OSA are overweight or obese. Thus, regardless of the mechanisms, the findings still appear to be of importance with regard to typical patients with OSA.

\section{Compensatory effectiveness}

Younes recently reported that most patients with OSA can compensate for anatomical abnormalities and restore ventilation without arousal from sleep at least some of the time, ${ }^{1}$ although effective compensation is less common with more severe mechanical loads. The current study also showed that ventilatory recovery is reduced with more severe loads (greater CPAP drop or increase in $\mathrm{R}_{\mathrm{UA80}}$ ). However, in contrast to the study by Younes, all patients with OSA in the current study could recover ventilation some of the time. This probably occurred because, rather than dropping the CPAP to $+\mathrm{l} \mathrm{cm} \mathrm{H}_{2} \mathrm{O}$, we performed a range of CPAP drops that induced a range of mechanical loads, some of which were quite mild (2$3 \mathrm{~cm} \mathrm{H}_{2} \mathrm{O}$ ). This is important, however, as it suggests that all individuals can compensate for minor impairments of pharyngeal patency.

The current study extends the findings of Younes by investigating the mechanisms of compensation and by comparing patients with OSA with healthy non-snorers. Both respiratory timing changes and increased genioglossus muscle activity were found during reduced CPAP in both subject groups. However, ventilatory recovery occurred less often in obese patients with OSA than in the non-snoring subjects. Although this difference was significant it was relatively small (54.1\% vs $65.7 \%$ of trials), and both groups were able to recover ventilation in many trials. However, this small difference may still make an important contribution to the pathogenesis of OSA, particularly during sleep without CPAP where patients with OSA will have greater degrees of airway collapse than non-snorers.

It is possible that the reduced ability to restore ventilation in OSA occurred because the same change in CPAP caused a greater degree of airway collapse in obese patients with OSA 
than in non-snorers. However, we do not believe this to be the case for two reasons. First, ventilatory recovery also occurred less often in patients with OSA when assessed in increments of resistance rather than CPAP drop (fig 2B). Second, the slope of the PIF/ $\mathrm{P}_{\text {MASK }}$ relationship between airway closure $\left(\mathrm{P}_{\mathrm{CRIT}}\right)$ and fully therapeutic CPAP was not different between groups, which suggests that similar CPAP changes should induce similar reductions in airflow. Thus, although both groups were able to recover ventilation less often with greater degrees of airway collapse (fig 2), for any given level of collapse the patients with OSA recovered less often than non-snorers. This result may have occurred because the increased electrical activity of the genioglossus muscle has a greater dilating effect on the airway of healthy non-snorers. Alternatively, the nonsnorers may have used another mechanism to restore ventilation that was not measured in this study and that could not be used by the patients with OSA. An example may be increasing end expiratory lung volume with increased caudal traction on the upper airway. ${ }^{19-21}$

In contrast to the current study, a previous report of five healthy men in whom CNAP was applied during sleep ${ }^{10}$ revealed that inspiratory time and genioglossus EMG increased across 20 breaths at $-7.5 \mathrm{~cm} \mathrm{H}_{2} \mathrm{O}$. However, tidal volume and minute ventilation (as measured by Respitrace) did not increase until arousal from sleep occurred. There are numerous differences between the studies which may explain the disparate results (see online supplement available at http:// thorax.bmj.com/supplemental). However, most notably, the mean pressure level was much less negative in the current study $\left(-0.11 \mathrm{~cm} \mathrm{H}_{2} \mathrm{O}\right.$ in the non-snorers $)$ and therefore probably induced less severe pharyngeal collapse.

\section{Genioglossus muscle activity}

The activity of the genioglossus has long been recognised to be higher in patients with OSA than in healthy subjects during wakefulness. ${ }^{14}$ In the current study, the slope of the $\mathrm{EMG}_{\mathrm{GG}}$ / $\mathrm{P}_{\mathrm{EPI}}$ relationship was similar between subjects with and without OSA during stable sleep. However, the tonic activity did not differ between groups and the epiglottic pressures were minimised by nasal CPAP. Thus, during stable sleep on CPAP, genioglossus activity was not different between subjects with and without OSA. This finding was somewhat unexpected. However, we are unaware of data comparing genioglossus activity between patients with and without OSA while both groups are on CPAP and in stable NREM sleep. We speculate that, when the effects of NREM sleep (loss of wakefulness drive and reduced negative pressure responsiveness) are combined with CPAP (decreased negative pressure drive to the muscle and increased lung volume), the muscle activation is similar in patients with OSA and non-snorers.

The genioglossus muscle was activated similarly in both subject groups regardless of whether or not recovery of ventilation occurred (figs 3 and 4). However, both peak and mean inspiratory flows were increased more in non-snorers than in patients with OSA by the end of the pressure drop (fig 3). This finding suggests either that the genioglossus is more effective at re-opening the upper airway in non-snorers or that they used some other mechanism to re-open their airway (such as increased lung volume). Given the known anatomical abnormalities in OSA, it seems likely that the effect of a given change in genioglossus activity may differ between groups. ${ }^{22}$ However, it is also possible that neuromuscular coupling differences exist such that the same electrical activity results in a lower muscle force in patients with OSA. Further studies will be required to determine why the genioglossus is less effective at restoring airflow in OSA.

\section{Respiratory timing}

Little attention has been paid to respiratory timing changes during sleep as a mechanism for increasing ventilation during partial airway obstruction, potentially because changes in breath timing with airway loading are considerably smaller during sleep than wakefulness. ${ }^{11}$ However, with the application of external inspiratory resistive loads, ${ }^{11}{ }^{12}$ reductions in $\mathrm{CPAP}^{10}$ and with hypercapnia, ${ }^{12}$ clear increases in the proportion of the breath spent inspiring have been observed during stable sleep. The magnitude of the change in respiratory timing in the current study was approximately $10 \%$ above baseline and is comparable to previous studies. ${ }^{11}{ }^{12}$ Thus, although changes in respiratory timing during sleep are small, they are likely to make an important contribution to the level of ventilation during partial airway collapse.

\section{Limitations}

There are several methodological limitations to this study that need to be considered. First, arousals were scored according to the ASDA criteria ${ }^{15}$ so it is possible that we missed subtle "subcortical" or "autonomic" arousals from sleep. We therefore quantified autonomic arousals ${ }^{23} 24$ and found that only $6 \%$ of pressure drops without cortical arousals had evidence of autonomic arousal (for details see online supplement available at http://thorax.bmj.com/supplemental). In all such cases ventilatory recovery had already occurred. We therefore believe that the results are not importantly influenced by the definition of arousal used.

Second, some of the pressure drops where recovery occurred may never have reduced ventilation sufficiently to cause blood gas disturbance and arousal from sleep. This could not be avoided because the level of ventilation below which arousal occurs could not be measured and is likely to vary between subjects. However, we attempted to minimise this effect by only analysing trials where flow limitation occurred. Also, if anything, we would expect this to occur more often in patients with OSA than in non-snorers because we reduced CPAP less in patients with OSA, making a difference between subject groups more difficult to detect.

Third, the non-snorers were often placed on CNAP during pressure drops whereas patients with OSA were always on positive pressure. CNAP may stimulate negative pressure receptors in the airway and cause greater muscle activation in non-snorers than in patients with OSA. However, muscle activation increased similarly in both groups so we doubt that this is an important problem, although it cannot be completely excluded.

Fourth, patients with OSA generally arouse at more negative epiglottic pressures than healthy subjects. ${ }^{25}$ This finding also occurred in the current study with the average epiglottic pressure on the breath before arousal being -8.7 (0.9) $\mathrm{cm} \mathrm{H}_{2} \mathrm{O}$ in non-snorers and $-13.7(1.8) \mathrm{cm} \mathrm{H}_{2} \mathrm{O}$ in patients with OSA $(p=0.02)$. A lower arousal threshold (more negative epiglottic pressures) could yield more pressure drops with ventilatory recovery in obese patients with OSA as they may have greater time for activation of compensatory mechanisms. However, this would tend to yield more trials where successful recovery occurred in the OSA group, the opposite of our findings.

Finally, it should be noted that the patients with OSA in this study reported nightly use of CPAP for at least 3 months before participation in the study. Treated patients with OSA were studied to minimise potential confounders such as airway oedema from repeated airway collapse and higher arousal thresholds from sleep fragmentation. However, the results may have been different had patients with untreated OSA been studied because sensory deficits or upper airway muscle dysfunction may be present in untreated patients. ${ }^{26-29}$ 
In summary, this study indicates that obese patients with OSA are less able to restore ventilation during stable sleep than non-snorers, despite similar increases in genioglossus muscle activity and changes in respiratory timing. In all subjects ventilatory recovery could occur at least some of the time, but the ability to restore ventilation was reduced with greater degrees of airway impairment. Thus, patients with OSA are not only likely to have greater airway collapse at sleep onset due to their poor pharyngeal anatomy, but are also less likely to be able to recover ventilation following airway collapse. Future investigations into why patients with OSA are less able to restore airflow and ventilation despite similar increments in muscle activation and changes in respiratory timing are warranted. Improving the ability to recover ventilation during sleep may provide a target for future therapeutic agents.

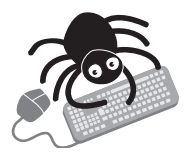

Further methodological details are given in the online supplement available at http://thorax.bmi.com/ supplemental.

\section{Authors' affiliations}

Amy S Jordan, Andrew Wellman, Raphael C Heinzer, Yu-Lun Lo, Karen Schory, Louise Dover, Atul Malhotra, David P White, Sleep Disorders Research Program, Brigham and Women's Hospital and Harvard Medical School, Boston, USA

Shiva Gautam, General Clinical Research Center, Beth Israel Deaconess Medical Center, Boston, USA

This study was supported by a grant from the American Heart Association and by the NIH grants P50 HL60292, AG024837-01, HL73146-01 and M01 RR01032.

Competing interests: None.

\section{REFERENCES}

1 Younes MK. Role of arousals in the pathogenesis of obstructive sleep apnea. Am J Respir Crit Care Med 2004; 169:623-33.

2 Horner RL, Innes JA, Morrell MJ, et al. The effect of sleep on reflex genioglossus muscle activation by stimuli of negative airway pressure in humans. J Physiol (Lond) 1994;476:141-51

3 Malhotra A, Trinder J, Fogel R, et al. Postural effects on pharyngeal protective reflex mechanisms. Sleep 2004;27:1105-12.

4 Wheatley JR, Mezzanotte WS, Tangel DJ, et al. Influence of sleep on genioglossus muscle activation by negative pressure in normal men. Am Rev Respir Dis 1993;148:597-605.

5 Wheatley JR, Tangel DJ, Mezzanotte WS, et al. Influence of sleep on response to negative airway pressure of tensor palatini muscle and retropalatal airway. J Appl Physiol 1993;75:2117-24.
6 Stanchina ML, Malhotra A, Fogel RB, et al. Genioglossus muscle responsiveness to chemical and mechanical stimuli during non-rapid eye movement sleep. Am J Respir Crit Care Med 2002;165:945-9.

7 Lo Y, Jordan AS, Malhotra A, et al. Genioglossal muscle response to $\mathrm{CO}_{2}$ stimulation during NREM sleep. Sleep 2006;29:470-7.

8 Okabe S, Hida W, Kikuchi Y, et al. Upper airway muscle activity during REM and non-REM sleep of patients with obstructive apnea. Chest 1994;106:767-73.

9 Onal E, Lopata $M, O^{\prime}$ Connor T. Pathogenesis of apneas in hypersomnia-sleep apnea syndrome. Am Rev Respir Dis 1982;125:167-74.

10 Aronson RM, Onal E, Carley DW, et al. Upper airway and respiratory muscle responses to continuous negative airway pressure. J Appl Physiol 1989;66:1373-82.

11 Wiegand L, Zwillich CW, White DP. Sleep and the ventilatory response to resistive loading in normal men. J Appl Physiol 1988;64:1186-95.

12 Schneider H, Patil SP, Canisius S, et al. Hypercapnic duty cycle is an intermediate physiological phenotype linked to mouse chromosome 5. J Appl Physiol 2003:95:11-9.

13 Jordan AS, McEvoy RD, Edwards JK, et al. The influence of gender and upper airway resistance on the ventilatory response to arousal in obstructive sleep apnoea in humans. J Physiol 2004;558:993-1004.

14 Mezzanotte WS, Tangel DJ, White DP. Waking genioglossal electromyogram in sleep apnea patients versus normal controls (a neuromuscular compensatory mechanism). J Clin Invest 1992;89:1571-9.

15 American Sleep Disorders Association Task Force. EEG arousals: scoring rules and examples. Sleep 1992;15:173-84.

16 American Sleep Disorders Association Task Force. Sleep-related breathing disorders in adults: recommendations for syndrome definition and measurement techniques in clinical research. Sleep 1999;22:667-89.

17 Jordan AS, Wellman A, Edwards JK, et al. Respiratory control stability and upper airway collapsibility in men and women with obstructive sleep apnea. J Appl Physiol 2005;99:2020-7.

18 Schwartz AR, O'Donnell CP, Baron J, et al. The hypotonic upper airway in obstructive sleep apnea: role of structures and neuromuscular activity. Am J Respir Crit Care Med 1998;157:1051-7.

19 Heinzer RC, Stanchina ML, Malhotra A, et al. Lung volume and continuous positive airway pressure requirements in obstructive sleep apnea. Am J Respir Crit Care Med 2005;172:114-7

20 Stanchina ML, Malhotra A, Fogel RB, et al. The influence of lung volume on pharyngeal mechanics, collapsibility, and genioglossus muscle activation during sleep. Sleep 2003;26:851-6.

21 Heinzer RC, Stanchina ML, Malhotra A, et al. Effect of increased lung volume on sleep disordered breathing in sleep apnoea patients. Thorax 2006;61:435-9.

22 BuSha BF, Strobel RJ, England SJ. The length-force relationship of the human genioglossus in patients with obstructive sleep apnea. Respir Physiol Neurobiol, 2002;130, 161-8.

23 Martin SE, Wraith PK, Deary IJ, et al. The effect of nonvisible sleep fragmentation on daytime function. Am J Respir Crit Care Med 1997;155:1596-601.

24 Trinder J, Allen N, Kleiman J, et al. On the nature of cardiovascular activation at an arousal from sleep. Sleep 2003;26:543-51.

25 Berry RB, Kouchi KG, Der DE, et al. Sleep apnea impairs the arousal response to airway occlusion. Chest 1996;109:1490-6.

26 Kimoff RJ, Sforza E, Champagne V, et al. Upper airway sensation in snoring and obstructive sleep apnea. Am J Respir Crit Care Med 2001;164:250-5.

27 Larsson H, Carlsson-Nordlander B, Lindblad LE, et al. Temperature thresholds in the oropharynx of patients with obstructive sleep apnea syndrome. Am Rev Respir Dis 1992;146:1246-9.

28 Leiter JC, Knuth SL, Bartlett D Jr. The effect of sleep deprivation on activity of the genioglossus muscle. Am Rev Respir Dis 1985;132:1242-5.

29 Mortimore IL, Douglas NJ. Palatal muscle EMG response to negative pressure in awake sleep apneic and control subjects. Am J Respir Crit Care Med 1997;156:867-73.

\section{Take advantage of BMJ Journals' remarkable catalogue of titles with Related Collections}

No busy professional has time to browse through all pertinent journals to find relevant articles, but with Related Collections you no longer have to. Follow the "Related Collections" link from any article and use the "Show Collections from other Journals" to expand your search across all BMJ Journals. Or simply follow the "Browse by topic" link on the home page. By setting up your own collections and receiving email alerts every time an article is added to your chosen area, you can build up your own significant body of knowledge. 